\title{
FUNDAMENTAÇÃO TEÓRICA DA INTEGRAÇÃO REGIONAL E SUA IMPORTÂNCIA PARA OS PED
}

\section{Lito Nunes Fernandes ${ }^{1}$}

\begin{abstract}
Resumo:
$\mathrm{Na}$ atual globalização, a integração de países como estratégia de promoção do desenvolvimento, sustentabilidade socioeconômica e estabilidade política foi se transformando em estratégia e solução de diversos problemas para os países em desenvolvimento (PED). Sua fundamentação teórica se baseia em que são políticas que proporcionem a elevação da competitividade internacional. O objetivo deste artigo é o estudo teórico do fenômeno da integração com a finalidade de vincular sua vantagem ao desenvolvimento dos PED. Conclui-se que a integração é uma estratégia sine qua non mesmo que insuficiente para o desenvolvimento e a inserção dos PED na Globalização.
\end{abstract}

Palavras-chave: integração regional, PED, desenvolvimento, globalização.

\begin{abstract}
Resumen:
En la actual globalización, la integración de los países para promover el desarrollo, la sostenibilidad socioeconómica y la estrategia de la estabilidad política se estaba convirtiendo en la estrategia y la solución de muchos problemas para los países en desarrollo (PED). Su fundamento teórico se basa en políticas que están proporcionando el aumento de la competitividad internacional. El propósito de este artículo es el estudio teórico del fenómeno de la integración con el fin de vincular su liderazgo en el desarrollo de los países en desarrollo. Llegamos a la conclusión de que la estrategia de integración es una condición sine qua non incluso insuficiente para el desarrollo y la integración de los países en desarrollo en la globalización.
\end{abstract}

Palabras-clave: integración regional, países en desarrollo, desarrollo, globalización.

\begin{abstract}
:
By increasing interdependence of national economies, the international economics situation has been characterized by the formation of blocks of countries as a strategy to promote development, socio-economic sustainability and political stability. In the case of developing countries, integration results in solving many problems, from which the theoretical basis of it angular integration that they are policies that provide high international competitiveness. The aim of this paper is the theoretical study of phenomenon of integration in order to link their advantage with the development of countries. We concluded that integration is the key strategy even insufficient for the developing countries in actual globalization.
\end{abstract}

Key-words: regional integration, developing countries, development, globalization.

\footnotetext{
${ }^{1}$ Doutorando em Economia pela UFRGS e bolsista da CAPES. Mestre em Direção Financeira pela Universidad de Mondragon (Espanha), Licenciado em Contabilidade e Finanças pela Universidade de Ciego de Ávila (Cuba). Professor da Universidade Colinas de Boe, em Bissau.
} 


\section{CONSIDERAÇÕES INICIAIS}

Ao aumentar a interdependência das economias nacionais num mundo cada vez mais globalizado, o desenvolvimento nacional dos países depende cada vez mais das circunstâncias externas e da coerência estrutural dos sistemas monetários e financeiros internacionais. Assim, a conjuntura econômica internacional foi se caracterizando pela formação de blocos de países como estratégia de promoção do desenvolvimento, sustentabilidade socioeconômica e a estabilidade política.

Tratando-se dos países em desenvolvimento (PED), a integração dos seus pequenos países geograficamente próximos com vista a usufruir as vantagens decorrentes desse processo resulta, em última instância, a solução de diversos problemas da região. Ademais, a fundamentação teórica da integração encontra sua base angular em que são políticas que proporcionem a elevação da competitividade internacional (OCAMPO, 2006). A partir disto, a integração representa para muitos PED, um impulso para se posicionarem da melhor maneira na economia mundial, fortalecendo o poder de negociação e, ao mesmo tempo, se protegerem das conseqüências negativas da globalização.

$\mathrm{Na}$ atualidade, o maior reflexo do impacto na integração se encontra nos avanços econômicos e logros que vem alcançando a União Européia. Entretanto, a análise dos distintos processos de integração não deve apresentar as mesmas características nem semelhanças da integração européia, já que cada região apresenta suas próprias características e objetivos.

De fato, a integração regional que faz parte da teoria das organizações internacionais é um tema bastante amplo para ser discutido cabalmente neste trabalho. Neste sentido, o objetivo deste artigo é um breve estudo teórico deste fenômeno, avaliando seu conceito, motivos e vantagens, tomando como foco central os debates dos antigos e atuais autores com a finalidade vincular sua vantagem ao desenvolvimento dos PED.

Em relação à composição do trabalho, o mesmo está dividido em seis partes independentemente desta consideração inicial. A segunda parte traz a definição da integração regional que, na verdade, ainda não encontrou um consenso generalizado. Na terceira são apresentadas as causas e os objetivos da integração, destacando-se que os objetivos integracionistas dos PED diferem dos objetivos de países desenvolvidos. A quarta parte trás as diferenças básicas entre a integração e outros conceitos relacionados com os quais poderiam ser confundidos. Na quinta parte são apresentadas as vantagens da integração regional e a importância que têm para os PED. Na sexta 
parte são expostas as conclusões finais do artigo e, finalmente, as bibliografias revisadas.

\section{MULTIPLICIDADE CONCEITUAL DA INTEGRAÇÃO REGIONAL}

Com a internacionalização das economias por meio da multiplicação dos acordos e blocos econômicos regionais após a Guerra Fria, os Estados nacionais foram compelidos a buscar novas formas de integração, com o objetivo de fortalecer a economia nacional, de garantir a atratividade dos investimentos estrangeiro e de ampliar a participação de seus territórios na economia global (GARCIA, 2007).

Quando se fala da integração, o raciocínio lógico nos leva a intuir uma vaga noção de união de diversas partes, isto é, conota a idéia de um processo que leva a junção das partes anteriormente separadas para formar uma comunidade de interesses, sentimentos e atitudes comuns implicando uma interdependência e uma rede de relações entre seus membros (PERROUX, 1967).

Segundo Fernandes (2007), desde as primeiras civilizações, a integração via comércio tem servido de instrumento para a aproximação dos povos, portanto, a essência da integração é tão antiga como o próprio mundo e se encontra nas distintas etapas da vida humana: desde famílias passando por países, regiões, até a comunidade internacional, e varia em dependência de autores e ideologias.

A integração regional é muitas das vezes apresentada como um processo unidirecional que avança em fases sucessivas desde a criação de uma área de livre comércio até as formas mais profundas da integração (TORRENT, 2006). Segundo o mesmo autor, este enfoque não corresponde à realidade, sobretudo observando-o desde o ponto de vista estritamente empírico. Para ele, a realidade demonstra que a integração regional arranca de formas diferentes e seguem caminhos distintos, e ao longo do tempo também podem avançar em direções totalmente diferentes, muito embora todos esses caminhos compartilhassem alguns elementos comuns ${ }^{2}$.

\footnotetext{
2 Para Torrente (2006), a tese defendida por Bela Belassa de que existem cinco fases sucessivas da integração: zona de livre comércio, união aduaneira, mercado comum, união monetária e união política, não é verdadeira, podendo se constatado nos casos do NAFTA e MERCOSUL. O primeiro inclui aspetos muito importantes do mercado comum em matéria que vão mais além do comercio de bens (serviços, investimentos), e em qualquer caso muito mais amplos e importantes do que inclui o MERCOSUL, sem ter nem sequer planejado o passo precedente, da união aduaneira. Também o MERCOSUL tem rosado muitos temas próprios da união política sem ter avançado praticamente em nada em matéria de mercado comum. Nem mesmo o modelo padrão da União Européia seguiu a sucessão das fases, porque muitos aspetos relativos a mercado comum foram registrados desde o momento da constituição e não no momento posterior. Outro exemplo exorbitante é o caso do ASEAN que demonstra que o processo pode
} 
O termo integração regional articulado em seu variado campo, recebeu múltiplas definições, podendo ser influenciadas por dimensões econômicas, jurídicas, políticas, históricas, sociais e culturais (FERNANDES, 2007). Desde a perspectiva econômica, "integrar" significa configurar um espaço econômico mais amplo que os Estados nacionais, cujo objetivo é a eliminação de barreiras comerciais entre os países membros. Como comenta Myrdal (1967), a integração se define como o elo condutor de um grupo de países dentro de um determinado espaço geográfico, motivados por interesses comuns com vista a superar a fase do desenvolvimento econômico onde se encontram.

No nível jurídico-institucional, Mariano e Mariano (2002) comentaram que a integração representa ceder às competências dos Estados membros a uma instituição regional comum, que se caracteriza por dispor poderes superiores aos Estados individuais, sendo que esta instituição está formada por cada um dos representantes governamentais dos países membros e suas decisões têm autoridade direta e imediata sobre as ordens jurídicas nacionais.

Desde o ponto de vista político, Haas (1958) classifica a integração como um processo liderado pelas elites, líderes de grupos políticos ou tomadores de decisões, onde vigoram as trocas de centros de lealdades, expectativas e atividades políticas para um novo, cujas instituições possuem ou exigem jurisdição sobre os Estados nacionais pré-existentes. Anos mais tarde, o mesmo autor reafirmaria a conceitualização da integração como o processo pela qual os atores políticos, em diferentes cenários nacionais, são persuadidos a transferir suas lealdades, expectativas e atitudes políticas para um novo e mais largo centro (HAAS, 1968, p. 16).

Ainda nesta linha de raciocínio, De La Vega (2007) define a integração regional como o processo de união de dois ou mais estados, desenvolvendo certa solidariedade e interdependência entre si, com o objetivo de atingir as metas previamente estabelecidas num marco institucional comunitário, ou seja, supõe a criação de um novo ator, expressão da vontade comum acima das vontades nacionais.

Desde a óptica da segurança comunitária a integração representa a junção das forças individuais numa coletiva que permitiria a união dessas forças para combater um inimigo comum. Segundo Deutsch (1993), um mundo integrado mediante uma comunidade segura, não teria guerra e as disputas se resolveriam por outras vias, conformando uma zona de paz e bem estar para todos.

Outros autores como Bichara, Cunha e Lélis (2008), definiram a integração regional como um processo efetivo de integração econômica entre um conjunto de 
países, podendo produzir-se de forma espontânea ou através de atuações políticas concretas; traduzido na realização de diversos acordos como área de livre comércio, união aduaneira ou mercado comum etc. Segundo os mesmos autores, só existe uma integração econômica completa quando existe mobilidade de bens, serviços e fatores de produção e quando os mercados financeiros estão unificados.

De fato, independentemente das teorias, ideologias ou dimensões usadas, existe um denominador comum de todos os conceitos da integração em que ela pode ser definida como uma combinação das partes para formar um todo. Entretanto, ainda continua persistindo uma considerável confusão sobre o uso da terminologia integração, já que não existe um consenso universal aceite sobre seu conceito.

\section{ORIGEM, OBJETIVOS E MOTIVOS DA INTEGRAÇÃO REGIONAL}

Os indícios do surgimento da integração regional começaram a se manifestar quando iniciou o enfraquecimento do Estado-nação para resolver ou administrar os problemas que vinham enfrentando, isto é, quando a solução estaria fora de seu alcance decisório (GARCIA, 2007). Para a mesma autora, a limitação de solucionar determinados problemas de forma isolada foi um forte estimulo para os países cooperarem ou aceitar que em certos campos, a soberania deve ser exercida coletivamente.

Conseqüentemente, esta situação de perda parcial da soberania ${ }^{3}$ dos países provoca um dilema entre seus tomadores de decisão, tendo em conta que enfrentam um trade off entre reafirmar a soberania estatal por meio de decisões unilaterais ou aderir às instituições multilaterais (MARIANO E MARIANO, 2002). A partir desta realidade, começaram a aparecer alternativas de políticas nacionais ou regionais, que procurassem reduzir os efeitos negativos da globalização financeira, sobretudo nos países em desenvolvimento.

$\mathrm{Na}$ tentativa de apontar um período específico, a maior parte da literatura relaciona o surgimento da integração regional com a criação da Comunidade Européia na década de $1950^{4}$ e, esta, por sua vez, provocou manifestações similares em quase todos os continentes. Existem várias respostas para a explicação dos fenômenos

3 A soberania- principio pelo qual o Estado tem autoridade suprema sobre todas as questões atinentes a seu domínio territorial- é a pedra angular do atual sistema inter-estatal.

4 Nomeadamente com a criação da Comunidade Econômica Européia e da Comunidade Européia de Energia Atômica, em 1957, ambos resultantes em certa medida da Comunidade Européia de Carvão e Aço, constituído em 1951 e cujo tratado entrou em vigor em 1952. 
integracionistas e seus objetivos ou causas variam ao longo do tempo ${ }^{5}$ em dependência da geopolítica regional e níveis de desenvolvimento dos países, podendo ser econômicas, políticas ou de segurança e defesa.

Gilpin (2001) argumenta que as principais abordagens que os economistas basearam para explicar a integração regional, surgiram no novo institucionalismo e na nova economia política ${ }^{6}$ dependendo do contexto e das circunstâncias, mas, em todas elas existe um fator comum: a cooperação. Segundo aquele mesmo autor, a abordagem do novo institucionalismo assume que as instituições internacionais (incluindo as regionais) são estabelecidas para vencer falhas no mercado, resolver problemas de coordenação e/ou eliminar obstáculos à cooperação econômica.

Desvelar as motivações para a integração de um grupo de países não resulta ser uma tarefa fácil, até porque os países desenvolvidos e os países em desenvolvimento têm diferentes motivos para integrarem num bloco, existindo em ambos os casos uma dialética de interesses. Para algumas regiões em desenvolvimento, a expansão dos blocos econômicos é um reflexo das pressões provocadas pelas assimetrias do poder no plano internacional, aumentando os riscos econômicos e políticos dos países que permanecem fora dessa estrutura de blocos e solapando a possibilidade do país que opta por permanecer independente (OCAMPO, 2006).

Indo ao encontro do dito no parágrafo anterior, Belassa (1961) evidenciou de forma clara a distinção dos objetivos da integração regional entre países desenvolvidos e países em desenvolvimento. Para os primeiros, o autor cita três motivos para a formação dos blocos regionais, a saber: (i) suprimir a constante intervenção do Estado na atividade econômica; (ii) criação de uniões aduaneiras com vista a diminuir as flutuações cíclicas transmitidas por meio do comercio internacional e; (iii) renascimento e ao fortalecimento da economia, tendo em vista os fatores dinâmicos resultante do fenômeno da integração regional econômica. Para os segundos, elenca dois motivos: (i) crescimento econômico e; (ii) o desejo de emular o exemplo europeu e o esforço de compensar a desigualdade no comercio internacional.

\footnotetext{
5 No caso mais chamativo que é a União Européia, nos primórdios desta integração os motivos mais importantes se relacionavam com a questão de evitar guerras entre os países. Com o passar dos tempos, as razões foram se ampliando na medida em que se estendia a questões econômicas e políticas, sobretudo quando e sentiam ameaçados pela União Soviética. Entretanto, com o fim da Guerra Fria esse temor foi perdendo espaço para uma nova forma de ameaça: a competição econômica dentro de um mundo globalizado. Na África, por exemplo, os primeiro motivos integracionistas estavam relacionados com as lutas de libertação nacional, mas depois de conseguir esse objetivo, as atenções integracionistas viraram para o fortalecimento da cooperação e desenvolvimento econômico.

6 Ênfase nas ações políticas dos grupos de interesses e nas conseqüências distributivas do regionalismo econômico como acordos de livre comércio e uniões alfandegárias que para o autor têm conseqüências distributivas negativas para os não membros, e esse cria que dentro dos próprios membros existam vencedores e perdedores.
} 
Por outra parte, Page (2000) alega que a integração regional não nasceu do nada e esta condicionada por uma diversidade de precondições e fatores tais como: (i) $a$ geografia, aspecto importante que também inclui a facilidade de comunicação, muito embora esta precondição não se da sempre, nem mesmo entre países vizinhos; (ii) $a$ população, é um fator importante muito embora a experiência demonstre que a diferença de tamanho entre os Estados membros não necessariamente cria obstáculo para o êxito da integração, (iii) o tamanho da economia e a renda per capita são relevantes, muito embora também a experiência demonstre que existem muitas divergências neste aspecto.; (iv) congruência política que em muitas ocasiões pode ser um fator chave para a consecução dos objetivos; (v) aspetos comunitários como origem ou qualquer assunto comum do passado, revertem grande importância no avanço da integração.

Haas (1964) identifica quatro motivações básicas para uma integração regional: (i) o desejo de promover a segurança numa dada região, realizando a defesa conjunta contra a ameaça comum; (ii) promover a cooperação para obter o desenvolvimento econômico e maximizar o bem estar; (iii) interesse da nação mais forte em querer controlar e dirigir as políticas dos seus aliados menores, por meio de persuasão, de coerção ou de ambos e; (iv) a vontade comum de constituir a unificação de comunidades nacionais numa entidade mais ampla.

$\mathrm{Na}$ visão de Carneiro (2008), as causas econômicas a favor da regionalização voltada para o comércio entre os países baseiam-se nos seguintes pilares: a percepção de que o livre-comércio amplia as diferenças tecnológicas entre regiões, concentrando os frutos do progresso técnico; a possibilidade de a regionalização ser considerada uma política promotora de industrialização quando viabiliza expansão dos mercados nacionais e do comércio intra-regional por intermédio do acesso de cada país a um mercado maior para suas indústrias e uma maior especialização e; o fato da regionalização requerer uma cooperação especial entre os países da região de forma a estabelecer políticas comuns, investimentos em infra-estrutura para compensar os desequilíbrios inter-regionais.

Em suma, a integração possibilita o estabelecimento de objetivos comuns entre Estados, considerando tanto as pressões nacionais quanto internacionais sobre eles, e permite a constituição de normas de estruturas no seio de quais acordos podem ser concretizados. Facilita também a criação de consenso entre os atores sobre os comportamentos aceitáveis a serem compartilhados por todos ao promover maior intercambio de informações, sendo este um elemento essencial na cooperação, pois 
ajuda na adoção descentralizada de regras e no estabelecimento de padrões de desempenho a serem supervisionadas.

\section{DIFERENÇA ENTRE A INTEGRAÇÃO REGIONAL E OS CONCEITOS LIGADOS A ELA}

Antes de entrar na diferenciação da integração dos conceitos afins, deve-se reforçar que a atual globalização, devido suas características e circunstâncias, permite que o regionalismo aberto ou novo regionalismo se diferencie em grande medida do regionalismo da época passada. O termo regionalismo num sentido amplo significa aquelas iniciativas políticas, sociais e econômicas que transcendem o âmbito de um território nacional e que não necessariamente têm que ser protagonizadas pelos Estados ou estar unicamente destinadas a promover a integração regional (DE LA VEGA, 2007).

$\mathrm{Na}$ tentativa de distinguir o velho do novo regionalismo, Culpeper (2006) frisa que o velho regionalismo dos anos cinqüenta e sessenta (onde os bancos regionais de desenvolvimento são exemplos) se caracterizava por grupos de interesses orientados para dentro, motivados pelo desejo de substituir a ausência de liberalização multilateral e/ou manter distantes da liberação que existia.

Por outro lado, o novo regionalismo esta orientado para o exterior e motivado pelo desejo de facilitar a entrada no sistema de investimento do comércio multilateral com maior liberalização mundial. Portanto, o novo regionalismo - compatível com a globalização, se caracteriza pela maior abertura e procura de uma integração mais profunda através da qual os países participantes transcendem amplamente as medidas de aplicação nas fronteiras para harmonizar suas políticas econômicas.

De forma mais específica, Bichara, Cunha e Lélis (2008), corroboram que diferentemente do regionalismo dos anos cinqüenta e sessenta centrado no comércio internacional como forma de superar os obstáculos intrínsecos ao tamanho dos mercados na estratégia de industrialização por substituição de importação, no regionalismo aberto da atual globalização convivem processos mais complexos que envolvem comércios de mercadorias e serviços, patentes, relações financeiras, marcos regulatório em diferentes áreas, mobilidade da força de trabalho, e que pretendem ampliar não só as relações entre os países de uma determinada região, mas também com outros países e blocos regionais.

Muitas das vezes tem-se a impressão de que o estudo da integração regional é o mesmo que o estudo da cooperação regional, da coordenação regional, da multilateral 
ismo ou da globalização. Por tal motivo, a continuação se esclarece as diferencias conceitual da integração com os outros conceitos muito ligados a ela.

\section{a) Integração versus cooperação}

A integração regional muitas das vezes se confunde com a cooperação, em virtude de algumas similitudes; porém, a integração regional é mais ampla que a cooperação internacional, podendo resultar em novas unidades ou entidades políticas e refere-se ao processo efetivo da junção entre um grupo de países, que pode produzir-se de forma espontânea ou através de atuações políticas concretas, o que se traduz na realização de diferentes acordos (MARIANO E MARIANO, 2002). Entre os exemplos da integração mais importantes temos a União Européia, a Comunidade Econômica dos Estados da África Ocidental (CEDEAO), a União Econômica e Monetária dos Estados da África Ocidental (UEMOA), o Tratado de Livre Comércio da América do Norte (NAFTA, siglas em inglês, o Mercado Comum do Cone Sul - MERCOSUL).

Por sua vez, como representa pouco mais que um acordo casual de uma questão específica, uma simples cooperação não implica modificações nas políticas econômicas nacionais, mas simplesmente uma troca de informações e opiniões entre governos. Bichara, Cunha e Lélis (2008) comentaram que existe um processo de cooperação regional quando um grupo de países geograficamente próximos estabelece mecanismos políticos com o objetivo de alcançar metas conjuntas que individualmente seria difícil conseguir. Para estes autores, o exemplo de ASEA+3 constituida depois da crise financeira asiática é digno de mencionar, mesmo admitindo que ainda não exista uma evidência suficiente para justificar que a cooperação procura perseguir a integração regional.

Em fim, a cooperação pode ser entendida como uma etapa de transição ou uma precondição para a integração. A cooperação pode ser uma estratégia contextualizada e ser abandonada de acordo com a conveniência, enquanto a integração regional é bem mais complexa por tratar da submissão de parte da soberania a uma entidade supranacional, por tal razão, abandonar a integração pode gerar resistência e altos custos para os governos- desde que o processo tenha atingido um determinado patamar de interação entre as sociedades envolvidas - especialmente quando sua estrutura institucional ganha autonomia e legitimidade (MARIANO E MARIANO, 2002).

\section{b) Integração versus coordenação}

Segundo Sarriera, Cunha e Bichara (2008), a coordenação assume que os governos devem sentar-se a uma mesa para dialogar e decidir políticas comuns para 
alcançar determinados objetivos, ou seja, significa uma ação centrada dos países participantes com miras à realização do bem-estar global por meio da exploração comum da interdependência de suas economias, a conciliação dos objetivos de suas políticas econômicas e comerciais e a convergência dos seus interesses nacionais. Já na opinião de De La Vega (2007), a coordenação se refere a uma solidariedade conjuntural com objetivos modestos e geralmente políticos sem transferência de soberania por parte dos participantes e; constitui a primeira etapa da criação de um sistema regional de decisões vinculantes.

De acordo com as definições anteriores, pode-se dizer que a coordenação corresponde ao mecanismo através da qual os países modificam suas políticas econômicas numa direção considerada como benéfica para todos, tendo em conta as relações econômicas internacionais, isto é, considera a existência de organismos internacionais de decisão.

Ademais, vale dizer que a coordenação se diferencia da integração porque se baseia no respaldo da vontade e soberania dos estados membros, isto é, se caracteriza pela falta de uma autoridade comunitária. Neste sentido, Cooper (1985) argúi que a coordenação de políticas econômicas é racional e eficiente apenas quando existe um grau de interdependência econômica entre os países envolvidos, isto é, o grau de influência de uma economia em outra.

Por sua vez, Currie, Lavine e Vidals (1987) afirmam que as coordenações podem apresentar as seguintes características: (i) horizontais, isto é, relações entre Estados iguais e independentes; (ii) verticais, que representam as relações entre Estados desiguais num conjunto estruturado; (iii) políticas, definida como uma forma de planejar ou fixar conjuntamente ao menos um instrumento da política econômica; (v) econômica, uma extensão da cooperação.

No nível internacional, a coordenação é entendida como um sistema que impõe restrições principalmente relativas à autonomia, pois o país envolvido deve abdicar do controle unilateral das suas políticas econômicas em favor da decisão tomada por uma serie de países, ato similar a de país que integra num bloco regional. Desta forma, a coordenação constitui um mecanismo e princípio inerente ao processo de integração, ou seja, representa uma etapa previa para o processo da integração.

\section{c) Integração versus multilateralismo}

$\mathrm{Na}$ atualidade, o modo de conceber a integração regional é multilateral, e a OMC desempenha o papel de guarda-chuva e árbitro para a compatibilidade e complementaridade destes processos. A assinatura dos acordos do Uruguay Round e a criação da Organização Mundial do Comércio (OMC), são também consequências que 
importa caracterizar e ligar ao aparecimento dos novos dossiês para a discussão e as novas formas do investimento e deslocalização industrial (CARDOSO E CASTRO, 1995).

Evidentemente, como comentaram os mesmos autores, a OMC apresenta um quadro de maior previsibilidade e segurança para o comércio internacional que a organização que a precedeu (GATT). Portanto, com a criação da OMC que tem condições para restringir às praticas desleais, direitos antidumping e afastar as ameaças do unilateralismo, as regras multilaterais encontram uma autoridade e supervisão apoiada pelos países que a integram.

Portanto, diferentemente da GATT 47, a OMC exige dos signatários o respeito por cada uma das cláusulas de acordo em vigor, situem-se elas no nível do comércio, dos serviços, da propriedade intelectual, ou de outros memorandos subscritos, designadamente os que regulam as disputas entre os seus membros. Assinale-se ainda que ao contrário da GATT 47, os membros da OMC não representam somente os Estados e territórios aduaneiros, mas também são considerados membros os espaços econômicos, as uniões econômicas, as zonas de livre comércio, os Estados não reconhecidos internacionalmente, as zonas off-shore. Todos eles, independentemente de observadores, têm direito a voto (BIGGS, 2003).

Enfim, a dialética integração versus multilateralismo surge sob um novo contexto: a integração regional aparece consentânea com o multilateralismo e os efeitos de criação ou desvio de comércio são subalteralizados nos processos de decisão e avaliação. Neste quadro, para os agentes econômicos e os governos a integração deixa de representar uma ruptura com a inserção internacional para se transformar na nova forma de aumentar a concorrência inter-regional e melhorar assim a competitividade internacional.

\section{d) Integração versus globalização}

A globalização, mecanismo através da qual as grandes multinacionais, com ativos financeiros e tecnologias desenvolvidas, aplicam suas políticas monopólicas para controlarem o sistema econômico-comercial, financeiro e político do mundo (FERNANDES, 2008) se caracteriza pelo crescimento das atividades econômicas para além das fronteiras (economias de escala), possibilitando aos diversos atores em movimento migratório, buscar nas trocas e nos investimentos o lucro pela livre concorrência.

Essa livre concorrência é totalmente desigual, devido à disparidade de desenvolvimento, tecnologia e infra-estrutura dos países e atores participantes. 
Portanto, a globalização é seletiva, pois são selecionados os lugares, as atividades, os setores e segmentos para serem globalizados e assim desfrutar dos benefícios da globalização (ROMERO, 2002).

Para o mesmo autor, sendo um processo abrangente que ultrapassa as fronteiras, afetando os diversos setores da sociedade, os efeitos negativos da globalização também podem ser encontrados na incapacidade de regulamentar o capital especulativo, deixando as economias nacionais sujeitas à pura especulação, que em última instância gera crises, aumento de exclusão social, pobreza e um gap maior entre os países desenvolvidos e os do terceiro mundo. Por sua vez, a integração representa um conjunto de medidas tomadas pelos Estados regionais relativamente próximos para aumentar ou diminuir os obstáculos, aumentar as trocas comerciais, os investimentos e movimentos de fatores entre os países membros.

Tomado nesse nível de generalidade, Toussaint e Millet (2006) corroboram que a globalização é a imposição dos países hegemônicos de suas políticas exploratórias aos países pobres, e a integração é a resposta de forma conjunta dos países em desenvolvimento ante a marginalização que sofrem na globalização. A franca expansão do processo de integração, sobretudo nos PED, especialmente a partir da década de 1990, reforça a necessidade de proteção de seus mercados dos efeitos negativos da globalização.

Portanto, a globalização continua a perpetuar os países pobres, enquanto que a integração esta sendo uma fonte fundamental do desenvolvimento e combate a pobreza nos países em desenvolvimento (OCAMPO, 2006). A diferença entre a globalização e a integração radica em que a globalização provoca a marginalização dos países, enquanto que a integração fortalece os países, brindando uma maior coesão e harmonia.

\section{VANTAGENS DA INTEGRAÇÃO REGIONAL}

Antes de abordar as vantagens que pode oferecer o processo de integração para uma dada região, convém recordar que as precondições para o êxito de qualquer processo de integração - sobretudo quando os atores possuem alguns interesses em comum, havendo expectativas quanto à possibilidade de ganhos com a cooperação ou quando a variação no grau de institucionalização se reflita no comportamento dos Estados e seus comprometimentos, na tentativa de conseguir os objetivos preestabelecidos (TORRENTE, 2006).

No que respeita a repartição dos benefícios da integração entre os países, esta não apresenta uma metodologia firme e consensual. No seu trabalho intitulado "¿quién integra? ¿en beneficio de quién se realiza la integración?”, o economista francês 
François Perroux responde que os benefícios da integração não vão nem para a parte superior da sociedade nem para a parte inferior, mas sim para ambas as partes. Ou seja, a integração é feita em beneficio de todos dependendo da estrutura e sua vantagem a priori, deveria ser para todos (PERROUX, 1967).

Como já apontado, a integração como processo está subdividida em econômicocomercial, política-juridica, monetária, sócio-cultural etc. Portanto, quando se fala das vantagens do seu processo se refere exatamente às vantagens de cada uma dessas subdivisões de forma isolada. Sem cair na tentação de mencionar todas as vantagens de cada uma delas, se elencará algumas consideradas pertinentes.

No que diz respeito à vertente econômica, Tamames (1995) afirma que os argumentos teóricos em favor da integração formam um amplo repertório de reflexões, a saber: economias derivadas da produção em grande escala; intensificação da competência dentro de um mercado mais amplo; atenuação da balança de pagamento pela poupança de divisas convertíveis; possibilidades de desenvolver atividades dificilmente desenvolvidas pelos países de forma isolada; aumento do poder de negociação frente a terceiros países ou frente a outras agrupações; formulação mais coerente da política econômica, assim como a necessidade de introduzir no médio e longo prazo de reformas estruturais e; possibilidade de aceleração do desenvolvimento econômico.

Ainda neste âmbito, Culpeper (2006) afirma que existem varias razões econômicas que justificam uma maior cooperação financeira regional. O autor destaca que quando um grupo de países coopera no âmbito financeiro e se auto-ajudam a preencher as lacunas provocadas pelos mercados incompletos, aumentam o financiamento externo para vários propósitos e, geralmente, cobrem o déficit de financiamento externo para o desenvolvimento e aproveitam as economias de escala.

De forma mais específica, Murapa (2002) comenta que o beneficio fundamental da integração econômica regional estaria na utilização de vantagens comparativas dos países que normalmente se manifesta pelo estabelecimento de uma zona de livre comércio, envolvendo a remoção de barreiras tarifárias e não tarifárias; pelo estabelecimento de uma união alfandegária pela qual todas as restrições ao comércio e ao movimento dos agentes dentro de uma área são renovadas e pela harmonização de políticas econômicas, monetárias, fiscais, sociais e outras políticas setoriais, que seriam relevantes no processo de desenvolvimento da região.

Haas (1958) analisa esta questão desde outro ponto de vista, argumentando que o interesse dos economistas pela questão da integração econômica reside na sua potencialidade de proporcionar conhecimentos sobre processo de formação de 
comunidades no âmbito internacional. O mesmo autor alega que a verdadeira integração somente será possível quando o critério subjetivo das expectativas de certas elites é satisfeita. Portanto, se as elites mais importantes de certas regiões têm as suas expectativas convergidas com as demandas e os benefícios decorrentes da integração, surge uma mobilização que movimenta e sustenta o processo.

Em relação à integração monetária, Sarriera, Cunha e Bíchara (2008), comentam que a teoria econômica e a experiência histórica sugerem que a viabilidade da integração monetária esta condicionada por uma série de fatores tais como: (i) a profundidade dos vínculos comerciais e financeiros dos países que compõe o bloco, (ii) a mobilidade de fatores entre as economias e a flexibilidade dos mercados de fatores, (iii) o grau da convergência entre o ciclo econômico destes países (movimento conjunto de preços, renda etc.), (iv) a construção de uma base institucional adequada, que uniformize as políticas fiscais, monetárias, etc., e garanta a constituição de um ambiente de negócios onde distorções sejam minimizadas, de modo a evitar arbitragens regulatórias; e (v) a existência de "lideranças regionais" aptas e dispostas a pagar o preço da “unificação' criando estabilizadores institucionais que mitiguem os conflitos potenciais e reais.

Ainda no âmbito monetário, Ferrari-Filho e De Paula (2002) elencaram os seguintes benefícios econômicos de uma união monetária: (i) taxa de inflação na união monetária em geral é significativamente menor; (ii) os custos de transação e de hedge dos agentes em relação aos riscos da variação da taxa de câmbio são reduzidos ou eliminados; (iii) a eliminação das taxas alfandegárias harmoniza, tudo mais constante, os preços dos produtos da economia, colocando-os em linha com os preços internacionais (lei do preço único); (iv) as barreiras sobre mobilidade dos fatores de produção são removidas; e (v) a integração regional é estimulada.

$\mathrm{Na}$ vertente política, Torrente (2007) deixou bem claro que mesmo havendo uma vontade econômica em grande escala, se não houver uma manifestação política, todos os desejos integracionistas virão abaixo. De igual idéia, Haas (1958) corrobora que os estreitos vínculos das elites mais importantes ou organizações nacionais como partidos políticos, sindicatos, associações profissionais, organizações religiosas ou outras instituições semelhantes são essenciais para uma integração regional ampla e frutífera. 7

Tendo em conta que as regiões em desenvolvimento apresentam diferentes estágios do desenvolvimento, a integração não seria um processo isolado, mas sim um conjunto de estratégias de reestruturação econômica e política que até pode contribuir

7 A integração regional na sua vertente política permite os países do bloco enfrentar de forma conjunta a intervenção estrangeiro ou de qualquer outro inimigo que isoladamente seria impossível. 
a mitigar os conflitos militares e sublevações tribais que às vezes acontecem nos PED. Paralelamente, a integração permite o arranque do processo industrial com instalações de industriais inicialmente voltadas para o setor primário (como têxtil) ou alimentaria em virtude da sua baixa complexidade e, portanto, menor demanda por investimentos, permitindo desta forma ampliação do mercado consumidor e também maior diversidade dos produtos produzidos (ESTEVES, 2008).

Em síntese, a integração possibilita o estabelecimento de objetivos comuns entre Estados do mesmo bloco; estabelece a constituição de normas e estruturas por meio dos quais os acordos podem ser concretizados; facilita também a criação de consenso entre os atores sobre os comportamentos aceitáveis a serem compartilhados por todos; promove maior troca de informações em todos os níveis e sectores da sociedade e; no nível externo, oferece aos PED uma maior rapidez e fortaleza da capacidade negociadora e em maior âmbito.

\section{CONSIDERAÇÕES FINAIS}

A globalização das economias tem causado o aprofundamento das diferenças sociais e de exclusão por parte de uma grande parte da população dos PED. Neste sentido, a integração regional, que ainda não encontra um consenso em quanto ao seu conceito, representa para os PED com mercados nacionais muito pequenos e fragilizados, a oportunidade de unir seus esforços para perseguir o desenvolvimento.

De forma mais especifica, a integração significa a abolição de entraves em movimentos de mercadorias, pessoas e capitais, alargando a atuação da oferta e da procura, como resultado de uma política comum, visando à eliminação das distorções das políticas setoriais com o objetivo de usufruir de forma conjunta dos benefícios. Seu processo ganhou mais força nas últimas décadas tanto em termos quantitativos como qualitativos diante da Nova Ordem Econômica Mundial que exige a eliminação gradativa das diferenças econômicas e sociais entre os Estados para a viabilização de diversos graus de integração.

Na tentativa de colocar um período padrão do seu surgimento, a maior parte da literatura relaciona o surgimento da integração regional com a criação da Comunidade Européia, porém, sua verdadeira origem se relaciona com o inicio do enfraquecimento dos Estados nas suas funções de administradores isolada dos seus problemas; desta forma, os países não tiveram outra saída que aceitar a cessão de parte da soberania para serem administrados coletivamente. 
A opção pela integração constitui riscos para os Estados, porque não representa somente a cadência de parte de soberania nacional, mas também abrir portas a competição. Entanto, muitos Estados preferem entrar nesse risco, porque a integração se converteu num instrumento importante na luta contra a pobreza, subdesenvolvimento e inserção na economia global, sobretudo para os países em desenvolvimento (OCAMPO, 2006).

Suas razões e objetivos variam ao longo do tempo podendo ser econômicas, políticas, religiosas, dependendo do contexto e das circunstâncias, mas, a idéia implícita em todas elas é a cooperação. No aspecto puramente econômico, o argumento a favor da regionalização baseia-se na percepção de que o livre-comércio promove a industrialização ao estabelecer políticas comuns de investimentos em infra-estrutura para compensar os desequilíbrios intra-regionais. Paralelamente, o aspecto político é crucial no processo da integração porque mesmo havendo uma vontade econômica em grande escala, se não houver uma manifestação política, todos os desejos integracionistas virão abaixo.

De fato, independentemente de a integração ter uma origem eminentemente econômica, a dimensão política e social não se pode ignorada tendo em conta o aumento da interconexão dos cidadãos e suas culturas dentro dos blocos. Desta maneira, argumenta-se que na atual globalização e perante a constante discriminação dos PED, a integração regional se converte numa estratégia vital de inserção exitosa no comércio internacional e a perseguição do catching up, através da junção dos esforços individuais de seus Estados numa entidade única para a resolução dos conflitos de forma conjunta. Mas só a integração não é suficiente e tem que ser apoiada pelas políticas de desenvolvimento de cada um dos países de forma isolada.

\section{REFERÊNCIAS BIBLIOGRÁFICAS}

BADI, M. K. Ideologías y Experiencias de Integración Regional en África: problemas e perspectivas. Tesis Doctoral. Facultad de Ciencias Políticas, Departamento de Derecho Internacional Público y Relaciones Internacionales de la Universidad Complutense, Madrid, 1992.

BELASSA, B. Teoria de Integração Econômica. Tradução de Maria F. Gonçalves e Maria E. Ferreira. Lisboa: Livraria Clássica, 1961.

BIGGS, G. Solución de controversias sobre comercio e inversiones internacionales. Revista de la CEPAL 80, p.101-119, 2003. 
CARNEIRO, R. Globalização e integração regional. Cadernos de desenvolvimento, vol.3(5), dezembro, 2008.

CASTRO, A.; CARDOSO, F. J. Dinâmicas e espaços de integração. in: A Integração Aberta: um projecto da União Européia e do Mercosul. Instituto de Estudos Estratégicos Internacionais, Lisboa, 1995.

COOPER, R. Economic Interdependence and Coordination of Policies. In: R.W. Jones e P.B. Kenen (eds), Handbook of International Economies. Vol. 2, cap 23, pp.1195-1234, 1985 .

CULPEPER, R. Reforma de la arquitectura financiera mundial: el potencial de las instituciones regionales. In: OCAMPO, José Antonio (org). Cooperación financiera regional. Santiago de Chile: CEPAL, 2006.

CUNHA, A.; BICHARA, J.; LELIS , M. T. Integración Monetaria y Financiera en América del Sur y Asia. Latin American Research Review, vol.43, No.1, 2008.

CURRIE, D; LEVINE, P; VIDALS, N. International cooperation and Reputation in an Empirical Two-Bloc Model. CEPR Discussion Paper, n.189, 1987.

DE LA VEGA, L. Actores regionales y subregionales en África Subsahariana: socios y líneas de trabajo potenciales para la cooperación española. Fundación Carolina, Madrid, 2007.

DEUTSCH; K. The growth of Nations: Some Recurrent Patterns of Political and Social Integration. New York: Irvington publishing, 1993.

EGOSCOZABAL, A. Regionalismo, globalização e pobreza: alternativas para o desenvolvimento dos países africanos. IX Reunião de Economia Mundial. Madrid, Abril 2007.

ESTEVES, T. Integração regional na América Latina: Da CEPAL ao Consenso de Washington. Revista IDeAS, v.2,n.2, p.172-202, 2008.

FERRARI-FILHO, F.; DE PAULA, L. F. Será consistente a proposta de criação de uma União Monetária no Mercosul? Revista de Economia Política, vol.22, $n^{o} 2$ (86), abriljunho, 2002.

FINKELSTEIN, C. A organização Mundial do Comércio e a Integração Regional. Revista do Instituto de Pesquisa e Estudos, n. 19, 1997. 
GÁRCIA, V. A Dimensão Social dos Processos de Integração Regional: as estratégias do MERCOSUL e da União Européia. Dissertação apresentada na Universidade Federal de Santa Maria, para a obtenção de Mestre em integração latino-americano. Santa Maria, julho, 2007.

FERNANDES, J. A Integração Econômica como Estratégia para o desenvolvimento econômico na África Ocidental. Dissertação apresentada na Universidade Federal de Santa Catarina. Florianópolis, Abril de 2007.

FERNANDES, L. Las Raíces Históricas del Atraso Económico en África Subsahariana. Textos de Economia. Florianópolis, v.11, n.I, p.11-38, 2008.

GILPIN, R. Global Political Economic: understanding the international Economic order. New Jersey: Princeton University Press, 2001.

HAAS, E. The uniting of Europe. Stanford: Stanford University Press, 1958.

Beyond the Nation-State: Functionalism and International Organization. Stanford: Stanford University Press, 1964.

.The Union of Europe: political, Social and Economic Forces. Stanford: Stanford University Press, 1968.

KENEN, P.B. Theory of optimum currency areas: an eclectic view. In: MUNDEL, Robert A.; SWOBODA, Alexander K. (eds). Monetary problems of the international economy. Chicago: University of Chicago Press, p. 41-60, 1969.

LOZA-VÁZQUEZ, M. A dimensão social do processo de integração regional na América Latina: atores e agentes da sociedade emergentes no MERCOSUL e NAFTA: os casos de Brasil e do México. Tese do doutorado da Sociologia apresentado na Faculdade de Ciências e Letras da UNESP, São Paulo, 2006.

MARIANO, M.; MARIANO, K. As teorias de integração regional dos Estados subnacionais. Impulso $\mathrm{n}^{\mathrm{O}}$ 31, 2002.

McKINNON, R. Optimum Currency Areas. The American Economic Review, vol. 53, n. 4, p. 717-725, 1963 .

MYRDAL, G. Perspectivas de uma economia internacional. Rio de Janeiro: Editora Saga, 1967.

MUNDELL, R. The theory of optimum currency areas. American Economic Review, 51(4): 657-65, September, 1961. 
MURAPA, R. A Comunidade de Desenvolvimento da África Austral (SADC): rumo à integração política econômica. Impulso $n^{\circ} 31,2002$.

OCAMPO, J. A. La cooperación financiera: experiencias y desafíos. In: OCAMPO, José Antonio (org). Cooperación financiera regional. Santiago de Chile: Libros de la CEPAL, 2006, p 13-55.

PAGE, S. Regionalism among Developing Countries. London: Macmillan Press, 2000.

Regionalism Among Developing Countries. London: Macmillan Press, 2006. PERROUX, François. ¿Quién integra? ¿En beneficio de quien se realiza la integración? Revista de la integración $n^{0_{1}}$, noviembre, 1967.

ROMERO, A. Globalización y Pobreza. Bogotá: Edicciones Unariño, 2002.

SARRIERA, J.; CUNHA, A.; BICHARA, J. Moeda Única no Mercosul: uma análise da simetria de choques para o período 1995-2007. XXXVI Encontro Nacional de Economia, Salvador de Bahia, 2008.

TAMAMES, R. Estructura Económica Internacional. Madrid: Alianza Editorial, 1995. TORRENT. R. Una aproximación a la anatomía del MERCOSUR real. Red Mercosur, 2006. Disponível em: http://www.redmercosur.org.uy/?q=node/57. Acesso em: 30/Outubro/ 2010.

TOUSSAINT, É; MILLET, D. 50 Perguntas 50 Respostas sobre a dívida, o FMI e o Banco Mundial. São Paulo: Boitempo Editorial, 2006. 